\title{
PSYCHOSOCIAL WORK STRESS, LEISURE TIME PHYSICAL EXERCISE AND THE RISK OF CHRONIC PAIN IN THE NECK/SHOULDERS: LONGITUDINAL DATA FROM THE NORWEGIAN HUNT STUDY
}

RANNVEIG FANAVOLL ${ }^{1}$, TOM IVAR LUND NILSEN ${ }^{1}$, ANDREAS HOLTERMANN ${ }^{2}$, and PAUL JARLE MORK ${ }^{1}$

${ }^{1}$ Norwegian University of Science and Technology, Trondheim, Norway

Department of Public Health and General Practice

${ }^{2}$ National Research Centre for the Working Environment, Copenhagen, Denmark

\begin{abstract}
Objectives: To prospectively investigate if the risk of chronic neck/shoulder pain is associated with work stress and job control, and to assess if physical exercise modifies these associations. Material and Methods: The study population comprised 29496 vocationally active women and men in the Norwegian Nord-Trøndelag Health Study (HUNT Study) without chronic pain at baseline in 1984-1986. Chronic neck/shoulder pain was assessed during a follow-up in 1995-1997. A generalized linear model (Poisson regression) was used to calculate adjusted relative risks (RRs). Results: Work stress was dosedependently associated with the risk of neck/shoulder pain $\left(\mathrm{p}_{\text {trend }}<0.001\right.$ in both sexes). The women and men who perceived their work as stressful "almost all the time" had multi-adjusted RRs $=1.27$ (95\% confidence interval (CI): 1.1-1.47) and 1.71 (95\% CI: 1.46-2), respectively, referencing those with no stressful work. Work stress interacted with $\operatorname{sex}(\mathrm{p}<0.001)$. Poor job control was not associated with the risk of neck/shoulder pain among the women (RR = 1.04, 95\% CI: 0.92-1.19) nor the men $(\mathrm{RR}=1.09,95 \% \mathrm{CI}$ : 0.95-1.26). Combined analyses showed an inverse dose-dependent association between hours of physical exercise/week and the risk of neck/shoulder pain in the men with no stressful work $\left(\mathrm{p}_{\text {trend }}=0.05\right)$ and among the men who perceived their work as "rarely stressful" $\left(\mathrm{p}_{\text {trend }}<0.02\right)$. This effect was not statistically significant among the women or among men with more frequent exposure to work stress. Conclusions: Work stress is an independent predictor of chronic neck/shoulder pain and the effect is stronger in men than in women. Physical exercise does not substantially reduce the risk among the persons with frequent exposure to work stress.
\end{abstract}

Key words:

Neck pain, Physical exercise, Work stress, Shoulder pain, Job control, Epidemiology

\section{INTRODUCTION}

Chronic pain in the neck/shoulders represents a significant and costly health problem of the working population [1-4]. Recent meta-analyses indicate that work-related psychosocial factors, such as: low social support, low job control, low decision authority, high job strain and monotonous work, are associated with a moderate increase in the risk of chronic neck/shoulder pain [5,6]. High levels of the perceived work stress have been associated with an increased risk of neck/ shoulder pain in some studies [7,8], while others have found no such an association [9]. Moreover, it is unclear whether stressful work has a different effect in women and men.

Received: February 11, 2015. Accepted: August 17, 2015.

Corresponding author: P.J. Mork, Norwegian University of Science and Technology, Department of Public Health and General Practice, Håkon Jarls gate 11, N-7491 Trondheim, Norway (e-mail: paul.mork@svt.ntnu.no). 
Additionally to workplace factors, lifestyle may play an important role in the aetiology of neck/shoulder pain. Longitudinal studies have shown that leisure time physical exercise reduces the risk of chronic neck/shoulder pain [10-14], while obesity increases the risk [14,15]. Physical exercise has also been shown to attenuate the adverse effect of excess body mass on the risk of chronic neck/shoulder pain $[14,16]$. It may, therefore, be hypothesized that physical exercise has a compensatory effect on other possible risk factors for neck/shoulder pain, such as stressful work.

A study on Finnish municipal administrative workers has reported that high levels of work related mental stress and a low frequency of physical exercise were associated with a nearly sevenfold increased risk of neck pain compared to workers with a low stress level and high exercise frequency [17]. However, we are not aware of any large-scale prospective studies that have investigated the relation between psychosocial work stress, leisure time physical exercise and the risk of neck/shoulder pain in a general, adult working population.

We used longitudinal data from a large population-based health survey in Norway to prospectively examine independent associations of the perceived work stress and job control with the risk of chronic neck/shoulder pain, and to assess if leisure time physical exercise modifies these associations.

\section{MATERIAL AND METHODS}

\section{Study population}

The Nord-Trøndelag Health Study (HUNT Study) is a large population-based health study conducted in the county of Nord-Trøndelag, Norway. All inhabitants aged $>20$ years were invited to participate, first in 1984-1986 (HUNT1) and then in the years 1995-1997 (HUNT2). A total of $77212(89.4 \%)$ persons accepted the invitation to participate in HUNT1, and in HUNT2, 65237 (69.5\%) persons participated. In the case of both surveys, the participants filled in questionnaires and attended a clinical examination. The procedures were similar in HUNT1 and HUNT2, although the questionnaires and the clinical examination were more comprehensive in the latter survey. The HUNT Study is a collaboration between the HUNT Research Centre (Faculty of Medicine, Norwegian University of Science and Technology), the NordTrøndelag County Council and the Norwegian Institute of Public Health.

A detailed description of selection procedures, questionnaires and measurements can be found on the Norwegian University of Science and Technology website [18]. Briefly, information was collected on a range of lifestyle and health-related factors, including medical history, occupational and leisure-time physical activity, smoking status, alcohol consumption and educational attainment. In the clinical examination, standardized anthropometric measures were obtained, i.e., height was measured to the nearest centimetre, weight to the nearest $0.5 \mathrm{~kg}$, and waist and hip circumference to the nearest centimetre. The study was approved by the Regional Committee for Ethics in Medical Research, and all the participants signed a written consent for participation in the HUNT Study. For the purpose of the present study we included all the 45925 persons (24 357 women and 21568 men) who participated in both surveys. We excluded the participants who reported to be without work (4003 women and 3014 men), worked full-time housework (5987 women and 73 men), or who had missing information on occupational status (31 women and 19 men). To obtain a study sample without chronic neck/shoulder pain at baseline (at the time of HUNT1), we excluded 3349 women and 3227 men who reported any chronic pain with duration $\geq 10$ years in HUNT2, and 105 women and 103 men without information on this variable. Moreover, we excluded 125 women and 76 men with missing data on the perceived work stress or job control, as well as 7 women without information on body mass index (BMI). This left a total of 10750 women and 15056 men available for prospective analyses of 
work stress and job control. Moreover, analyses of baseline physical exercise included 8925 women and 12693 men due to missing data on 4188 persons.

\section{Study variables}

\section{Psychosocial work stress}

In the 1st questionnaire in HUNT1 (baseline) the participants were asked about the perceived work stress and job control. The question on the perceived work stress was: "Does your work involve a lot of stress and hassles?" Response options were: "no, not at all," "rarely," "yes, a certain amount," and "yes, almost all the time." For job control the question was: "Do you decide how your work is planned?" Response options were: "no, not at all," "a little," "yes, for the most part," and "yes, I decide."

\section{Chronic neck/shoulder pain}

The questions about musculoskeletal symptoms were adopted from the Standardized Nordic Questionnaire [19]. During the follow-up (HUNT2) the participants were asked: "During the last year, have you had pain and/or stiffness in your muscles and limbs that lasted for at least 3 consecutive months?" Response options were: "yes" and "no." If the participants answered "yes," they were asked to specify the pain-afflicted body area(s) and to specify duration of the symptoms, i.e., the number of months if the symptoms lasted $<1$ year and the number of years if the symptoms lasted $>1$ year. In the statistical analyses, chronic pain in the neck, shoulders, and upper back were combined to indicate chronic neck/shoulder pain.

\section{Physical exercise}

At baseline (HUNT1) the participants answered questions on frequency, intensity and duration of their leisure time physical exercise (e.g., walking, skiing, swimming, or other sports). The frequency question had 5 response options ( 0 times per week, $<1$ time per week, 1 time per week, 2-3 times per week, $\geq 4$ times per week). We defined the participants who reported no exercise or $<1$ exercise session per week as inactive. The participants who reported exercising once a week or more were also asked about the average duration per session $(<15 \mathrm{~min}, 15-30 \mathrm{~min}$, 31-60 $\mathrm{min},>60 \mathrm{~min}$ ) and the average exercise intensity (no sweat or heavy breathing, i.e., low; sweat and/or heavy breathing, i.e., moderate; and nearly exhausted, i.e., high). Due to a small number of people who reported high exercise intensity, in the statistical analyses moderate and high intensity were combined into 1 category.

We also estimated the average hours of physical exercise per week calculated as the product of frequency and duration. For the purpose of this calculation, a frequency of "once per week" was coded as 1 session, "2-3 times per week" was coded as 2.5 sessions, and " $\geq 4$ times per week" was coded as 5 sessions. Correspondingly, a duration of "< 15 min" was coded as $10 \mathrm{~min}$, "15-30 min" was coded as $25 \mathrm{~min}$, "30-60 min" was coded as $45 \mathrm{~min}$, and "> 60 min" was coded as 75 min per session.

\section{Statistics}

A generalized linear model with a log link function (i.e., Poisson regression) was used to estimate risk ratios (RRs) for chronic neck/shoulder pain. The participants who reported different levels of the perceived work stress were compared with the reference group of the participants that reported no exposure to stressful work. The RRs for chronic neck/shoulder pain between categories of job control were estimated in similar models. Analyses of the perceived work stress, job control, and the risk of chronic neck/shoulder pain were stratified by gender. The precision of the estimated RRs was assessed using 95\% confidence intervals (CI). Tests for trends across categories of the perceived work stress and job control were conducted by treating the categories as an ordinal variable in the regression model.

The basic models were adjusted for age at baseline (continuous). In additional multivariable analyses, we 
adjusted for BMI (body mass divided by the squared value of the height $\left(\mathrm{kg} / \mathrm{m}^{2}\right)$, continuous), smoking (never, former, current, unknown (7.4\%)), occupation (non-manual, manual, unknown $(9 \%)$ ), education ( $\leq 9$ years, 10 12 years, $>12$ years, unknown $(8.2 \%)$ ), leisure time physical exercise (inactive, 1 session per week, 2-3 sessions per week, $\geq 4$ sessions per week, unknown (7.6\%)), and psychological well-being (good, fair, poor, unknown (7.5\%)). Additionally, we conducted a stratified analysis to examine whether leisure time physical exercise modified the association between the perceived work stress and the risk of neck/shoulder pain. To formally assess the possible interaction we included a product term of exercise frequency and work stress as well as exercise intensity and work stress in the regression model. The combined effect of the perceived work stress and hours of leisure time physical exercise was assessed using the workers who reported no work stress and who were physically inactive as the reference group. The combined effect of the perceived work stress and exercise intensity was analysed in a similar model, using the workers who reported no work stress and who were physically inactive as the reference group. We also assessed the possible linear effect ( $p$ from trend test) of physical exercise and intensity of exercise within each strata of work stress. All the analyses were conducted using Stata for Windows, version 11.0 (StataCorp LP, USA).

\section{RESULTS}

Table 1 presents characteristics of the study population according to the levels of the perceived work stress and job control at baseline, respectively. In the followup, 3118 (29\%) women and 3486 (23.2\%) men reported chronic pain in neck/shoulders.

Table 2 shows the age- and multi-adjusted RRs of chronic neck/shoulder pain in the follow-up associated with the perceived work stress and job control at baseline.

Table 1. Baseline characteristics of the study population according to the perceived work stress and job control

\begin{tabular}{lcccccccc}
\hline & \multicolumn{4}{c}{ Perceived work stress } & \multicolumn{4}{c}{ Job control } \\
\cline { 2 - 9 } Variable & not at all & rarely & $\begin{array}{c}\text { a certain } \\
\text { amount }\end{array}$ & $\begin{array}{c}\text { almost all } \\
\text { the time }\end{array}$ & I decide & $\begin{array}{c}\text { for the most } \\
\text { part }\end{array}$ & a little & not at all \\
\hline Women $(\mathrm{N}=10750)[\mathrm{n}]$ & 1484 & 3917 & 4788 & 561 & 1031 & 4875 & 3674 & 1170 \\
age [years] $(\mathrm{M} \pm \mathrm{SD})$ & $45.8 \pm 12.9$ & $41.0 \pm 11.7$ & $40.4 \pm 11.1$ & $39.4 \pm 10.6$ & $45.3 \pm 12.9$ & $41.6 \pm 11.7$ & $39.6 \pm 10.9$ & $42.3 \pm 11.9$ \\
BMI [kg/m²] $(\mathrm{M} \pm \mathrm{SD})$ & $24.7 \pm 3.9$ & $24.0 \pm 3.7$ & $23.7 \pm 3.5$ & $23.7 \pm 3.6$ & $24.6 \pm 3.9$ & $24.0 \pm 3.6$ & $23.7 \pm 3.6$ & $24.1 \pm 3.7$ \\
current smoker [\%] & 29.8 & 29.0 & 27.8 & 29.8 & 27.9 & 26.6 & 29.8 & 33.9 \\
education $\geq 13$ years [\%] & 2.0 & 8.7 & 16.9 & 17.1 & 7.8 & 14.4 & 12.2 & 3.5 \\
manual worker [\%] & 27.2 & 16.5 & 12.7 & 14.1 & 18.9 & 15.0 & 15.1 & 22.0 \\
physically inactive [\%] & 28.7 & 32.0 & 31.9 & 26.4 & 31.5 & 30.1 & 31.6 & 32.3 \\
Men (N = 15 056) [n] & 1287 & 5381 & 7290 & 1098 & 2385 & 7809 & 4046 & 816 \\
age [years] $(\mathrm{M} \pm \mathrm{SD})$ & $47.7 \pm 15.4$ & $41.6 \pm 12.9$ & $41.3 \pm 11.3$ & $40.5 \pm 10.4$ & $45.2 \pm 13.1$ & $42.0 \pm 12.0$ & $39.9 \pm 12.0$ & $41.3 \pm 13.1$ \\
BMI [kg/m²] $(\mathrm{M} \pm \mathrm{SD})$ & $25.3 \pm 3.1$ & $24.9 \pm 2.9$ & $25.0 \pm 2.9$ & $25.1 \pm 3.1$ & $25.3 \pm 3.0$ & $25.0 \pm 2.9$ & $24.9 \pm 2.9$ & $25.2 \pm 3.2$ \\
current smoker [\%] & 28.0 & 28.3 & 28.5 & 28.7 & 26.0 & 26.9 & 31.4 & 34.6 \\
education $\geq 13$ years [\%] & 3.6 & 8.6 & 16.0 & 19.2 & 8.3 & 16.1 & 10.1 & 2.2 \\
manual worker [\%] & 29.8 & 35.0 & 27.2 & 21.6 & 9.1 & 25.6 & 45.2 & 54.0 \\
physically inactive [\%] & 37.8 & 36.2 & 36.2 & 40.0 & 39.4 & 35.2 & 36.8 & 40.7 \\
\hline
\end{tabular}

$\mathrm{M}$ - mean; SD - standard deviation; BMI - body mass index.

${ }^{\text {a }}$ No activity or $<1$ exercise session per week. 
Work stress was positively and dose-dependently associated with the risk of chronic neck/shoulder pain in both women and men ( $\mathrm{p}_{\text {trend }}<0.001$ in both sexes). Compared to those who reported no stressful work, the women and men who perceived their work as stressful almost all the time had multi-adjusted RRs $=1.27(95 \% \mathrm{CI}$ : $1.1-$ 1.48 ) and 1.71 (95\% CI: 1.46-2), respectively. Poor job control was not clearly associated with the increased risk of chronic neck/shoulder pain, i.e., the women and men who reported to have no job control at all had multi-adjusted RRs $=1.04$ (95\% CI: 0.92-1.19) and 1.09 (95\% CI: 0.95-1.26), respectively.

Table 3 shows the combined effect of the perceived work stress and physical exercise on the risk of chronic neck/shoulder pain. Overall, there was no clear effect of physical exercise among the women in any of

Table 2. Relative risk of chronic neck/shoulder pain among the women and men in the 11-year follow-up associated with the perceived work stress and job control at baseline

\begin{tabular}{|c|c|c|c|c|c|c|}
\hline \multirow[b]{2}{*}{ Variable } & \multirow{2}{*}{$\begin{array}{c}\text { Respondents } \\
(\mathrm{N}=25806) \\
{[\mathrm{n}]}\end{array}$} & \multirow{2}{*}{$\begin{array}{c}\text { Cases with pain } \\
(\mathrm{N}=6604) \\
{[\mathrm{n}]}\end{array}$} & \multicolumn{2}{|c|}{$\mathrm{RR}$} & \multirow[b]{2}{*}{$95 \% \mathrm{CI}$} & \multirow[b]{2}{*}{$\mathrm{p}_{\text {trend }}$} \\
\hline & & & age-adjusted & multi-adjusted $^{a}$ & & \\
\hline \multicolumn{7}{|l|}{ Women $(\mathrm{N}=10750)$} \\
\hline work stress & & & & & & $<0.001$ \\
\hline not at all & 1484 & 385 & 1.00 & 1.00 & reference & \\
\hline rarely & 3917 & 1071 & 1.04 & 1.06 & $0.96-1.17$ & \\
\hline a certain amount & 4788 & 1470 & 1.16 & 1.19 & $1.08-1.32$ & \\
\hline almost all the time & 561 & 192 & 1.29 & 1.27 & $1.10-1.48$ & \\
\hline job control & & & & & & 0.100 \\
\hline I decide & 1031 & 298 & 1.00 & 1.00 & reference & \\
\hline for the most part & 4875 & 1345 & 0.94 & 0.95 & $0.85-1.05$ & \\
\hline a little & 3674 & 1101 & 1.01 & 1.01 & $0.91-1.12$ & \\
\hline not at all & 1170 & 374 & 1.09 & 1.04 & $0.92-1.19$ & \\
\hline \multicolumn{7}{|l|}{$\operatorname{Men}(\mathrm{N}=15056)$} \\
\hline work stress & & & & & & $<0.001$ \\
\hline not at all & 1287 & 217 & 1.00 & 1.00 & reference & \\
\hline rarely & 5381 & 1138 & 1.25 & 1.28 & $1.12-1.46$ & \\
\hline a certain amount & 7290 & 1829 & 1.49 & 1.56 & $1.37-1.77$ & \\
\hline almost all the time & 1098 & 302 & 1.63 & 1.71 & $1.46-2.00$ & \\
\hline job control & & & & & & 0.020 \\
\hline I decide & 2385 & 532 & 1.00 & 1.00 & reference & \\
\hline for the most part & 7809 & 1740 & 1.00 & 1.05 & $0.96-1.15$ & \\
\hline a little & 4046 & 1006 & 1.11 & 1.14 & $1.03-1.25$ & \\
\hline not at all & 816 & 208 & 1.14 & 1.09 & $0.95-1.26$ & \\
\hline
\end{tabular}

a Adjusted for age (continuous), body mass index (continuous), smoking (never, former, current, unknown), occupation (non-manual, manual, unknown), education ( $\leq 9$ years, 10-12 years, $\geq 13$ years, unknown), psychological well-being (good, fair, poor, unknown), and leisure time physical exercise (inactive, 1 session per week, $2-3$ sessions per week, $\geq 4$ session per week, unknown).

$\mathrm{RR}$ - risk ratio; $\mathrm{CI}$ - confidence interval. 


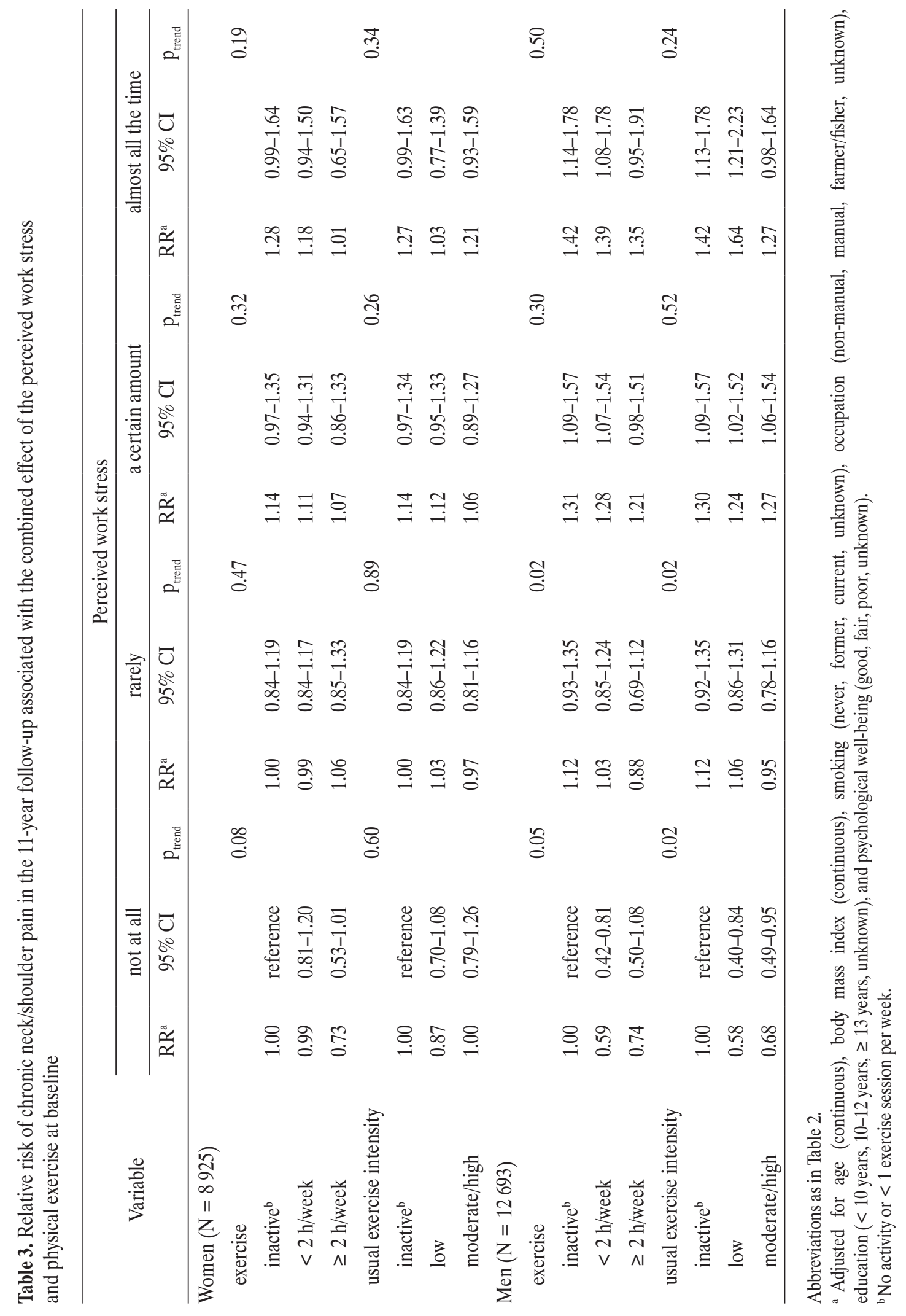


the categories of work stress, although the women who reported no work stress and exercised $\geq 2 \mathrm{~h}$ per week had a RR $=0.73$ (95\% CI: 0.53-1.01) compared to the reference group of inactive women with no work stress. However, in the men both hours of exercise and intensity of exercise were inversely associated with the risk of neck/ shoulder pain among those who reported no stressful work $\left(\mathrm{p}_{\text {trend }}=0.05\right.$ and 0.02 , respectively) and those who perceived their work as rarely stressful $\left(\mathrm{p}_{\text {trend }}=0.02\right.$ for both exercise measures). No clear association between physical exercise and the risk of neck/shoulder pain was observed among the men with more frequent work stress exposure (i.e., "a certain amount" or "almost all the time").

\section{DISCUSSION}

This longitudinal study shows that the perceived work stress is positively and dose-dependently associated with the risk of chronic neck/shoulder pain in the general working population. The perceived work stress interacted with sex, indicating a stronger effect of stressful work in the men than in the women. Poor job control was not associated with an increased risk of chronic neck/shoulder pain. Hours of leisure time physical exercise were associated with a dose-dependent reduction in the risk of chronic neck/shoulder pain among the men with no work stress and among the men who perceived their work as rarely stressful. This effect was not present among the women. Although there was no statistically significant effect of physical exercise on the risk of neck/shoulder pain within strata of more frequent stress exposures (i.e., "a certain amount" and "almost all the time"), we observed a small, but consistently lower, risk among the women and men who exercised $\geq 2 \mathrm{~h}$ per week compared to those who were inactive.

A few prospective studies have investigated the effect of stressful work on the risk of neck/shoulder pain. In a longitudinal study with repeated follow-up measurements over a period of 3 years, Viikari-Juntura et al. have found that mental stress was dose-dependently associated with the increased odds of radiating neck pain [8]. The study cohort comprised 5180 blue and white collar workers of a Finnish forest industry enterprise, and the case definition was radiating pain lasting for $\geq 8$ days the previous 12 months. In another longitudinal study, Harkness et al. have found no association between stressful work at baseline and the risk of shoulder pain in 12 months or 24 months follow-ups in workers representing 12 different occupations $(\mathrm{N}=638$ and $\mathrm{N}=476$ in 12 months and 24 months follow-ups, respectively) [9]. The exposure categories for the perceived work stress were dichotomized into "never/occasionally" and "at least $1 / 2$ of the time" and thus, resembling a fairly similar categorization as the one used in the current study. However, differently from our study the case definition was shoulder pain lasting $\geq 1$ day during the past month. It should also be noted that about $1 / 2$ of the workers in the study were entering the workforce at the time of the baseline measurement (i.e., taking up full time employment for the 1st time). The divergent finding from our study may, therefore, be explained by the noticeable differences in the study population, case definition as well as duration of the follow-up period. Therefore, the findings in the current study add novel information concerning the association between stressful work and the risk of chronic neck/shoulder pain in the general adult working population. Thus, workplace programs targeted to reduce frequent exposure to stressful work may potentially reduce the incidence of chronic pain in neck/shoulders.

Although we observed a somewhat higher incidence of chronic neck/shoulder pain among the women than men (29\% vs. $23.2 \%$ ), during the 11-year follow-up period, the association between stressful work and the risk of neck/shoulder was stronger in men than in women. A possible explanation for this sex difference is that multiple risk factors exist for chronic neck/shoulder pain and that those risk factors have different relative importance in women and men. This could include both sex-related biological 
and psychological factors (e.g., hormonal influences, coping strategies etc.) as well as environmental factors such as duties and stressors outside work [20].

In the current study, the workers who reported poor job control had no increased risk of chronic neck/shoulder pain compared to the workers with high job control. In a recent meta-analysis that included data from 11 longitudinal studies, poor job control has been identified as an independent risk factor for neck/shoulder pain [6]. However, it should be noted that the relative risk estimate for the workers with poor job control in the meta-analysis was only marginally higher than the age-adjusted relative risks found in the current study (i.e., $16 \%$ vs. $9-14 \%$ in the current study). Thus, both this study and findings from previous longitudinal studies indicate that poor job control is not a strong risk factor for chronic neck/shoulder pain in the general adult working population.

Physiological pathway between the perceived work stress and development of neck/shoulder pain is currently unclear. A commonly cited hypothesis is that stressful work induces a sustained low-level muscle activity that in the long-run may lead to muscle overexertion and pain [21-23]. A recent review has shown that exposure to simulated stressful work, in a laboratory, results in a modest increase in muscle activity in neck/shoulder muscles and forearm muscles [24]. However, the review has included mainly laboratory studies, which does not necessarily mirror stress exposure or stress response in the workplace. A field study of female computer workers with recordings of muscle activity in neck/shoulders along with concurrent hourly reports of the perceived work stress throughout the workday has shown no evidence of an association between stressful work and an elevated muscle activity [25]. Likewise, there is no sound evidence to support the notion that an elevated or sustained (low-level) muscle activity in the workplace is associated with neck/shoulder pain [26]. Thus, a model suggesting that the stress-induced muscle activity leads to neck/shoulder pain lacks empirical support and future studies are needed to identify the mechanisms by which work stress induces neck/shoulder pain.

Physical exercise has been indicated to have a favourable effect on the risk of neck/shoulder pain within the strata of men with no or rare exposure to stressful work. Although the effect of physical exercise was non-significant within all strata of stress exposure among the women and men with more frequent stress exposure, the risk was consistently lower among the men and women who exercised $\geq 2 \mathrm{~h}$ per week compared to those who were inactive (i.e., 7-27\% reduced risk within the 2 strata with highest level of work stress). Likewise, exercising with a moderate/high intensity was associated with a somewhat lower risk compared to inactivity and exercise with a low intensity.

Therefore, it is possible that a higher dosage of physical exercise will lead to a further reduction in the risk among those with frequent exposure to stressful work. Impact of interaction between mental stress and frequency of physical exercise on the risk of neck pain among office workers has been reported by Korhonen et al. [17]. Although the study included a selected and a rather small study sample $(\mathrm{N}=180)$, it supports the notion that physical exercise can compensate for the unfavourable effect of stressful work on the risk of chronic musculoskeletal pain. There are several strengths of the current study, such as: its prospective design, large population, exclusion of the persons with chronic neck/shoulder pain at baseline and information on several potentially confounding factors. Occurrence of chronic neck/shoulder pain in HUNT2 was assessed by the Nordic questionnaire, which permits a sensitive and reproducible assessment of musculoskeletal symptoms [27,28]. Moreover, the questions on leisure time physical exercise in HUNT1 have been validated against measurement of maximal oxygen uptake in a random sample of men, and they were found to perform well with a correlation coefficient of 0.48 [29]. However, the questions do not contain any information about the type of exercise; hence, the independent effect of different types 
of exercise (e.g., strength vs. endurance exercise) in preventing chronic neck/shoulder pain could not be assessed. Some previous studies indicate that the strength exercise may have a more positive effect on alleviating neck/shoulder pain than the endurance exercise [30,31].

A limitation of our study is that the perceived work stress and the level of job control were assessed by single items. Both the question on job control and on the perceived work stress may have diverse meanings in different occupations, thereby, capturing a large range of different psychosocial work stress exposures. Moreover, the perceived work stress may have different impact on the risk of neck/shoulder pain in different occupations, depending on the interaction with other variables such as physical work demands. Nevertheless, it may be argued that the term work stress has strong face validity across different occupations, i.e., people across different types of occupations are likely to have a fairly similar perception of what is meant by the term work stress. Although the data were collected in the 1980s and 1990s, we believe that the association between psychosocial work stress and the risk of chronic neck/shoulder pain is highly relevant for the current working life.

We adjusted for factors known to affect the risk of neck/ shoulder pain, but the difference between the age-adjusted and multivariable-adjusted risk estimates was small and residual confounding due to the unknown, and unmeasured confounders cannot be ruled out. Missing data on possible confounders among some persons (up to 9\%) could also contribute to residual confounding. Moreover, we did not adjust for environmental factors or stressors outside work that may differ between the women and men (e.g., housework, child care). Our finding that work stress has a more profound impact in the men than women should, therefore, be interpreted cautiously. Further, the healthy worker effect may have influenced our results, i.e., workers that developed chronic neck/shoulder pain during the followup left the workforce and did not participate in HUNT2.
Finally, another limitation of the study is that information on the exposure variables (i.e., physical exercise, work stress, and job control) work was obtained only at baseline, and changes during the follow-up period could not be taken into account.

\section{CONCLUSIONS}

This prospective study indicates that the women and men who perceive their work as stressful most of the time have an increased risk of chronic neck/shoulder pain. The effect of stressful work is more pronounced among the men than among the women. Poor job control was not associated with an increased risk of chronic neck/shoulder pain. Leisure time physical exercise does not substantially reduce the adverse effect of stressful work on the risk of chronic neck/shoulder pain.

\section{REFERENCES}

1. Côté P, Kristman V, Vidmar M, van Eerd D, Hogg-Johnson S, Beaton D, et al. The prevalence and incidence of work absenteeism involving neck pain - A cohort of Ontario lost-time claimants. Spine. 2008;33:S192-8, http://dx.doi.org/10.1097/ BRS.0b013e3181644616.

2. Côté P, van der Velde G, Cassidy JD, Carroll LJ, HoggJohnson S, Holm LW, et al. The burden and determinants of neck pain in workers - Results of the bone and joint decade 2000-2010 task force on neck pain and its associated disorders. Spine. 2008;33:S60-74, http://dx.doi.org/10.1097/ BRS.0b013e3181643ee4.

3. Andersen LL, Mortensen OS, Hansen JV, Burr H. A prospective cohort study on severe pain as a risk factor for longterm sickness absence in blue- and white-collar workers. Occup Environ Med. 2011;68:590-2, http://dx.doi.org/10.1136/ oem.2010.056259.

4. Andersen JH, Haahr JP, Frost P. Risk factors for more severe regional musculoskeletal symptoms: A two-year prospective study of a general working population. Arthritis Rheum. 2007;56:1355-64, http://dx.doi.org/10.1002/art.22513. 
5. Lang J, Ochsmann E, Kraus T, Lang JWB. Psychosocial work stressors as antecedents of musculoskeletal problems: A systematic review and meta-analysis of stability-adjusted longitudinal studies. Soc Sci Med. 2012;75:1163-74, http:// dx.doi.org/10.1016/j.socscimed.2012.04.015.

6. Hauke A, Flintrop J, Brun E, Rugulies R. The impact of work-related psychosocial stressors on the onset of musculoskeletal disorders in specific body regions: A review and meta-analysis of 54 longitudinal studies. Work Stress. 2011;25:243-56, http://dx.doi.org/10.1080/02678373. 2011.614069.

7. Bongers PM, Ijmker S, van den Heuvel S, Blatter BM. Epidemiology of work related neck and upper limb problems: Psychosocial and personal risk factors (Part I) and effective interventions from a bio behavioural perspective (Part II). J Occup Rehabil. 2006;16:279-302, http://dx.doi.org/10.1007/ s10926-006-9044-1.

8. Viikari-Juntura E, Martikainen R, Luukkonen R, Mutanen P, Takala EP, Riihimaki H. Longitudinal study on work related and individual risk factors affecting radiating neck pain. Occup Environ Med. 2001;58:345-52, http://dx.doi. org/10.1136/oem.58.5.345.

9. Harkness EF, Macfarlane GJ, Nahit ES, Silman AJ, McBeth J. Mechanical and psychosocial factors predict new onset shoulder pain: A prospective cohort study of newly employed workers. Occup Environ Med. 2003;60:850-7, http://dx.doi.org/10.1136/oem.60.11.850.

10. Holth H, Werpen H, Zwart JA, Hagen K. Physical inactivity is associated with chronic musculoskeletal complaints 11 years later: Results from the Nord-Trøndelag Health Study. BMC Musculoskelet Disord. 2008;9:159, http://dx.doi.org/10.1186/1471-2474-9-159.

11. Van den Heuvel SG, Heinrich J, van der Beek AJ, Bongers PM. The effect of physical activity in leisure time on neck and upper limb symptoms. Prev Med. 2005;41:260-7, http://dx.doi.org/10.1016/j.ypmed.2004.11.006.

12. Hildebrandt VH, Bongers PM, Dul J, van Dijk FJH, Kemper HCG. The relationship between leisure time, physical activities and musculoskeletal symptoms and disability in worker populations. Int Arch Occup Environ Health. 2000;73:507-18, http://dx.doi.org/10.1007/s00420 0000167.

13. Miranda H, Viikari-Juntura E, Martikainen R, Takala EP, Riihimaki H. A prospective study of work related factors and physical exercise as predictors of shoulder pain. Occup Environ Med. 2001;58:528-34, http://dx.doi.org/10.1136/ oem.58.8.528.

14. Nilsen TIL, Holtermann A, Mork PJ. Physical exercise, body mass index, and risk of chronic pain in the low back and neck/shoulders: Longitudinal data from the Nord-Trøndelag Health Study. Am J Epidemiol. 2011;174:267-73, http:// dx.doi.org/10.1093/aje/kwr087.

15. Kääriä S, Laaksonen M, Rahkonen O, Lahelma E, LeinoArjas P. Risk factors of chronic neck pain: A prospective study among middle-aged employees. Eur J Pain. 2012;16: 911-20, http://dx.doi.org/10.1002/j.1532-2149.2011.00065.x.

16. Mork P, Vasseljen O, Nilsen T. Association between physical exercise, body mass index, and risk of fibromyalgia: Longitudinal data from the Norwegian Nord-Trøndelag Health Study. Arthritis Care Res (Hoboken). 2010;62:611-7, http:// dx.doi.org/10.1002/acr.20118.

17. Korhonen T, Ketola R, Toivonen R, Luukkonen R, Häkkänen M, Viikari-Juntura E. Work related and individual predictors for incident neck pain among office employees working with video display units. Occup Environ Med. 2003;60:47582, http://dx.doi.org/10.1136/oem.60.7.475.

18. Norwegian University of Science and Technology (NTNU) [Internet]. Levanger: The University, 2016 [cited 2015 Feb 10]. The HUNT Study - A longitudinal population health study in Norway. Available from: http://www.ntnu. edu/hunt.

19. Kuorinka I, Jonsson B, Kilbom A, Vinterbergh H, BieringSørensen F, Andersson G, et al. Standardized Nordic questionnaires for the analysis of musculoskeletal symptoms. Appl Ergon. 1987;18:233-7, http://dx.doi.org/10.1016/00036870(87)90010-X. 
20. Lundberg U, Mardberg B, Frankenhaeuser M. The total workload of male and female white collar workers as related to age, occupational level, and number of children. Scand J Psychol. 1994;35:315-27, http://dx.doi.org/ 10.1111/j.1467-9450.1994.tb00956.x.

21. Sjøgaard G, Lundberg U, Kadefors R. The role of muscle activity and mental load in the development of pain and degenerative processes at the muscle cell level during computer work. Eur J Appl Physiol. 2000;83:99-105, http://dx.doi. org/10.1007/s004210000285.

22. Visser B, de Looze MP, de Graaff MP, van Dieën JH. Effects of precision demands and mental pressure on muscle activation and hand forces in computer mouse tasks. Ergonomics. 2004;47:202-17, http://dx.doi.org/10.1080/001401303100 01617967.

23. Lundberg U. Psychophysiology of work: Stress, gender, endocrine responses, and work-related upper extremity disorders. Am J Ind Med. 2002;41:383-92, http://dx.doi. org/10.1002/ajim.10038.

24. Eijckelhof BH, Huysmans MA, Bruno Garza JL, Blatter BM, van Dieen JH, Dennerlein JT, et al. The effects of workplace stressors on muscle activity in the neck-shoulder and forearm muscles during computer work: A systematic review and meta-analysis. Eur J Appl Physiol. 2013;113(12):2897-912, http://dx.doi.org/10.1007/s00421-013-2602-2.

25. Mork P, Westgaard R. The influence of body posture, arm movement, and work stress on trapezius activity during computer work. Eur J Appl Physiol. 2007;101:445-56, http://dx.doi.org/10.1007/s00421-007-0518-4.
26. Mork P, Westgaard R. Low-amplitude trapezius activity in work and leisure and the relation to shoulder and neck pain. J Appl Physiol. 2006;100:1142-9, http://dx.doi.org/10.1152/ japplphysiol.01111.2005.

27. Descatha A, Roquelaure Y, Chastang JF, Evanoff B, Melchior M, Mariot C, et al. Validity of Nordic-style questionnaires in the surveillance of upper-limb workrelated musculoskeletal disorders. Scand J Work Environ Health. 2007;33:58-65, http://dx.doi.org/10.5271/ sjweh.1065.

28. Palmer K, Smith G, Kellingray S, Cooper C. Repeatability and validity of an upper limb and neck discomfort questionnaire: The utility of the standardized Nordic questionnaire. Occup Med (Lond). 1999;49:171-5.

29. Kurtze N, Rangul V, Hustvedt BE, Flanders WD. Reliability and validity of self-reported physical activity in the Nord-Trøndelag Health Study: HUNT 1. Scand J Public Health. 2008;36:52-61, http://dx.doi.org/ 10.1177/1403494807085373.

30. Andersen LL, Kjær M, Søgaard K, Hansen L, Kryger AI, Sjøgaard G. Effect of two contrasting types of physical exercise on chronic neck muscle pain. Arthritis Rheum. 2008;59:84-91, http://dx.doi.org/10.1002/ art.23256.

31. Andersen LL, Andersen CH, Zebis MK, Nielsen PK, Søgaard K, Sjøgaard G. Effect of physical training on function of chronically painful muscles: A randomized controlled trial. J Appl Physiol. 2008;105:1796-801, http://dx.doi.org/ 10.1152/japplphysiol.91057.2008.

This work is available in Open Access model and licensed under a Creative Commons Attribution-NonCommercial 3.0 Poland License - http://creativecommons.org/ licenses/by-nc/3.0/pl/deed.en. 